\title{
Shift Workers at Risk for Metabolic Syndrome
}

Kshma Kulkarni, OMS IV; Marie Schow, OMS III; Jay H. Shubrook, DO

From Touro University

California in Vallejo.

Disclaimer: Dr Shubrook, a JAOA associate editor, was not involved in the editorial review or decision to publish this article.

Financial Disclosures: None reported.

Support: None reported.

Address correspondence to

Jay H. Shubrook, DO, 1310 Club Dr, Mare Island, Vallejo, CA 94592-1187.

Email: jay.shubrook@tu.edu Submitted May 24, 2019; revision received October 2, 2019; accepted October 24, 2019.
In this highly digitalized era, sleep disorders are becoming more common and are associated with an increased burden of chronic disease. Shift workers are at an increased risk for both sleep disorders and metabolic syndrome. In this article, the authors outline the connection between circadian discordance, hormonal imbalance, and the development of metabolic syndrome in shift workers. Based on a literature review of animal model studies, observational studies, and clinical trials conducted between August and October of 2018, the authors offer several clinical interventions, including work schedules, light therapy, medications, and dietary habits to improve the circadian synchronicity of shift workers and reduce their risk of morbidity and mortality. It is important for physicians to be familiar with the consequences of shift work and ways to mitigate the risks for this patient population.

J Am Osteopath Assoc. 2020;120(2):107-117

doi:10.7556/jaoa.2020.020

Keywords: circadian rhythm, metabolic syndrome, shift work, sleep disorders any of the human body's neurohormonal cascades, including key metabolic cascades and the sleep-wake cycle, follow 24-hour rhythms. These circadian rhythms evolve in response to a light-dark cycle established by sunrise and sunset along with the daily rhythm of other external factors, such as temperature and noise. Today, people are exposed to synthetic light, heat, and other stimulating cues that do not follow a 24-hour cyclic pattern. These synthetic factors interfere with the carefully coordinated interplay between external regulators and the endogenous maintenance of circadian rhythms. ${ }^{1}$ Shift workers are increasingly affected by this phenomenon. ${ }^{2}$ This discordance among shift workers has been linked to disruption in the sleep-wake cycle and metabolic pathways, leading to sleep deprivation and an increased risk of metabolic syndrome. ${ }^{3}$

In this review, we discuss the relationship between metabolic syndrome and shift work. We completed PubMed searches in August and October 2018 using the following keywords: "shift worker demographics," "metabolic syndrome and shift workers," "risk factors associated with metabolic syndrome in shift work," "circadian rhythm and shift work," "cortisol release and shift work," "shift work and exercise habits," "shift work and nutrition habits," "circadian rhythm discordance and metabolic syndrome," "sleep hygiene and shift work disorder," "nutrition and sleep hygiene," "exercise and cortisol release," "sleep disorders and shift work," "sleep disorders and metabolic syndrome," "osteopathic manipulation and sleep latency," "shift work and heart rate variability," and "osteopathic manipulation and heart rate variability." Of the literature reviewed, 38 articles were experimental studies (animal model or clinical trials), 35 were review articles, and 17 were observational studies. Based on this literature 
review, we provide clinical recommendations to improve circadian rhythm in shift workers.

\section{Demographics of Shift Workers}

Previous research indicates that $17.7 \%$ of the US labor force is engaged in work outside the hours of $6 \mathrm{Am}$ to 6 PM. $^{2}$ The industries with the largest portion of their workforce engaged in shift work are leisure/hospitality, arts, entertainment, mining, transportation, and warehousing. ${ }^{2}$ Shift workers are more likely to work in lower-paying industries. ${ }^{2}$ One article ${ }^{4}$ highlighted that people tend to work outside of $6 \mathrm{Am}$ to $6 \mathrm{PM}$ before acquiring their college education. A study of retired shift workers found that a history of shift work remained an independent risk factor for diabetes and hypertension, even though sleep quality improved upon retirement. ${ }^{5}$ Nearly $6.5 \%$ of shift workers are assigned either irregular shift work or rotating shift work. ${ }^{2}$ These workers are at an even greater risk of circadian rhythm discordance. ${ }^{4-6}$

\section{The Relationship Between Metabolic Syndrome and Circadian Desynchrony}

Research shows that shift workers have an increased incidence of metabolic syndrome, ${ }^{3,6}$ which increases their risk for the metabolic trifecta of cardiovascular disease, strokes, and type 2 diabetes mellitus. ${ }^{7,8}$ Initially, it was believed that unhealthy lifestyle choices and lower socioeconomic status were largely responsible for increased risk among this population, but the data do not support this belief. For example, studies have found that night shift workers are not exercising less than the general population. ${ }^{9}$ They may even be exercising more than their day-shift counterparts. ${ }^{9,10}$

A growing body of research suggests that discordance with the circadian rhythm is an independent risk factor for the development of metabolic syndrome. Circadian rhythm is a bimolecular mechanism that keeps time for the body through both neural and hormonal signaling. ${ }^{11}$ When the circadian rhythm does not match the sleep-wake cycle, as seen in shift workers, it causes opposing signaling, termed circadian desynchrony. This desynchrony disrupts the suprachiasmatic nucleus network rhythm and the patterned hormonal release for which it keeps time, leading to disturbances in sleep and metabolism. Shift workers sleep less than non-shift workers and report feeling more tired than their day-working counterparts, all signs of circadian desynchrony. ${ }^{7,8,12}$ Some shift workers' circadian rhythms become so disrupted as to cause shift work sleep disorder-a sleep disorder characterized by insomnia and the inability to stay alert at work. ${ }^{1}$

People subject to circadian desynchrony exhibit several disturbances in hormonal levels, including increased cortisol and ghrelin and decreased thyroidstimulating hormone, growth hormone, insulin, leptin, and serotonin. ${ }^{13-16,18,19}$ For example, circadian desynchrony results in increased insulin and glucose levels and has been shown to occur independently of behavioral choices. ${ }^{4,17,18}$ Qian et $\mathrm{al}^{19}$ found that circadian desynchrony is specifically associated with decreased insulin sensitivity, which could explain the innately worse glycemic ranges found in shift workers Circadian desynchrony has a similar effect on ghrelin, increasing the appetite for energy-dense foods and postprandial ghrelin levels. ${ }^{19}$

These relationships substantiate the link between sleep disturbances and metabolic dysregulation. ${ }^{13}$ Hormonal cascades linked to the development of metabolic syndrome, such as the regulation of insulin, have a reciprocal relationship with our circadian rhythms. ${ }^{14}$ In a rat study, diet-induced insulin resistance led to circadian desynchrony, ${ }^{15}$ but insulin release has also been shown to cause reproducible phase-shift responses in circadian clock genes. ${ }^{16}$ The reciprocal relationship has also been seen with hormones such as cortisol and melatonin, as well neurotransmitters such as serotonin. Other hormones, including ghrelin, leptin, and adiponectin, could prove to have similar reciprocal relationships with circadian rhythm regulators. 
This information is key in determining current intervention recommendations.

\section{Clinical Assessments and Interventions}

\section{Sleep Hygiene}

Table 1 presents a sleep hygiene screening tool for shift workers. To maintain circadian synchrony and normal sleep architecture, shift workers should sleep in a single 7- to 8-hour block each 24 hours. Patients should choose a time to go to sleep each day, as close to the same time of day as possible. ${ }^{20,21}$ Tracking sleep has also been shown to be an effective way to maintain a consistent sleep schedule. ${ }^{22}$ Patients should be encouraged to use a sleep journal or phone application to track their sleep.

Because sleeping during the day is not practical for many night shift workers on off days, night shift workers can follow the phasic sleep schedule developed by Smith et al. ${ }^{23}$ This sleep schedule has been shown to improve circadian synchrony and increase total sleep time for shift workers ${ }^{23}$ (Table 2). Shift workers who sleep in the evenings rather than mornings report fewer circadian disruptions. ${ }^{24}$ To increase the quantity of sleep, shift workers can take 20- to 120-minute naps. ${ }^{1,25}$ Recuperative naps have been linked to decreased total sleep time, so shift workers can be encouraged to take prophylactic naps before the start of shifts. ${ }^{26}$

\section{Table 1.}

\section{Sleep Hygiene Screening Tool for Shift Workers}

\begin{tabular}{|c|c|}
\hline Question & Clinical Implication \\
\hline How much sleep do you get a night? & Paitents should sleep $\geq 7$ hours per night. \\
\hline What is your shift schedule like? & Patients should minimize rotating schedules. \\
\hline What hours of the day do you typically sleep? & $\begin{array}{l}\text { Patients should be encouraged to sleep in the evening if working the } \\
\text { night shift. }\end{array}$ \\
\hline What is your sleeping pattern on off days? & $\begin{array}{l}\text { Patients who work nights should shift their sleep cycle by } 5 \text { hours } \\
\text { instead of by } 12 \text {; patients who work early-morning or late-evening shifts } \\
\text { should attempt to adhere to a regular sleep schedule. }\end{array}$ \\
\hline How long after waking do you feel hungry? & $\begin{array}{l}\text { Not feeling hungry within } 1 \text { hour of waking may indicate circadian } \\
\text { dysrhythmia and cortisol imbalance. }\end{array}$ \\
\hline $\begin{array}{l}\text { Do you feel you are overeating or feel hungry all the } \\
\text { time? }\end{array}$ & $\begin{array}{l}\text { This is a sign of circadian desynchrony; possible causes include } \\
\text { elevated cortisol, insulin insensitivity, sleep deprivation, elevated } \\
\text { progesterone, and elevated ghrelin. }\end{array}$ \\
\hline 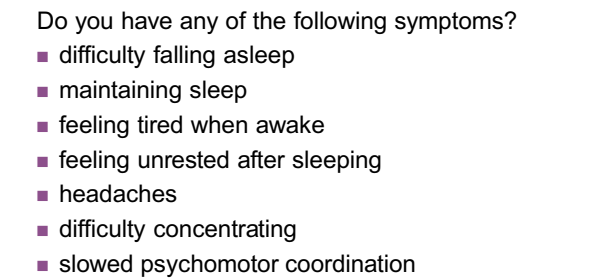 & Any of these symptoms may indicate a circadian sleep disorder. \\
\hline
\end{tabular}


Table 2.

Suggested Sleep Schedules for Overnight Shift Workers to Reduce Circadian Desynchrony ${ }^{a}$

\begin{tabular}{lcc} 
Event & $\begin{array}{c}\text { Evening Sleep } \\
\text { Schedule }\end{array}$ & $\begin{array}{c}\text { Morning Sleep } \\
\text { Schedule }\end{array}$ \\
\hline Bedtime & $1: 30$ PM-8:30 PM & $8: 30$ AM-3:30 PM \\
\hline $\begin{array}{l}\text { Last day of } \\
\text { night shift }\end{array}$ & $1: 30$ PM-6:30 PM & $8: 30$ AM-1:30 PM \\
\hline Off day & $6: 30$ PM-2:30 AM & $3: 30$ AM-10:30 AM \\
\hline
\end{tabular}

a These proposed schedules are examples for patients working a 10:30 PM to 7 AM shift with 2 days off per week, a schedule in which patients will most likely prefer to be awake during the daytime. Patients should be encouraged to find a sleep schedule that fits with their personal routine while minimizing adjustments between off days and on days of shift work.

\section{Types of Shift Work}

To maintain a consistent sleep pattern, it is better to work night shifts consistently rather than switch between night and day shifts to avoid constant circadian rhythm disruption. ${ }^{1}$ Working 11 hours or less and starting night shifts before midnight both reduce sleep drive. ${ }^{20,25,27}$ For those shift workers required to work a rotating shift schedule, the literature discusses 2 different transition techniques: (1) night-to-morning to evening-to-night and (2) night-to-evening to morning-to-night. Some research indicates that the first option reentrains sleep cycles more efficiently and leads to lower cortisol release. ${ }^{27}$ However, a 2018 study found no significant difference between these 2 strategies. ${ }^{28}$ Consistent schedules, work that begins before midnight, and shifts that last up to 11 hours can all optimize shift work to improve circadian reentrainment. Physicians should screen patients for rotating shift work and other maladaptive schedules. This knowledge can serve to identify patients who may benefit from other interventions and would be of educational value to patients. Suggested workplace modifications are presented in Table 3.

\section{Light}

Exposure to light promotes wakefulness. ${ }^{11}$ Light exposure upon waking will cause phase shift advance, pro-

\section{Table 3. \\ Employer Workplace Modifications for Shift Workers}

\begin{tabular}{|c|c|}
\hline Recommendation & Examples \\
\hline Decrease blue light exposure & $\begin{array}{l}\text { - Provide Redshift } \\
\text { application for digital } \\
\text { screens } \\
\text { - Use lightbulbs that block } \\
\text { blue lights } \\
\text { - Apply blue light filter to } \\
\text { head/eye gear }\end{array}$ \\
\hline Provide meals & $\begin{array}{l}\text { Recommend lean } \\
\text { proteins and fresh fruits } \\
\text { and vegetables } \\
\text { - Provide highest calorie } \\
\text { meal midway through } \\
\text { shift }\end{array}$ \\
\hline Promote health screenings & $\begin{array}{l}\text { Provide benefits that } \\
\text { cover yearly or biannual } \\
\text { health screening for } \\
\text { metabolic syndrome and } \\
\text { circadian desynchrony }\end{array}$ \\
\hline $\begin{array}{l}\text { Create health program that } \\
\text { promotes healthy behavior }\end{array}$ & $\begin{array}{l}\text { Provide incentive to use } \\
\text { health tracking } \\
\text { applications that track } \\
\text { health parameters like } \\
\text { sleep, diet, and exercise }\end{array}$ \\
\hline $\begin{array}{l}\text { Modify shift schedules to } \\
\text { ease burden of sleep debt }\end{array}$ & $\begin{array}{l}\text { Avoid rotating shift } \\
\text { schedules }\end{array}$ \\
\hline $\begin{array}{l}\text { Modify break times to allow } \\
\text { for earlier meal times }\end{array}$ & $\begin{array}{l}\text { Ensure that employees } \\
\text { can have the same break } \\
\text { time each day }\end{array}$ \\
\hline
\end{tabular}

moting transition in circadian rhythm. Conversely, exposure before sleep will cause phase shift delay, delaying circadian sleep drive. Shift workers can use this phenomenon to their advantage by increasing light exposure $^{26}$ just before and throughout work shifts. Reminding shift workers to control light exposure is a simple but effective tool to promote timely sleep.

The intensity of lighting can also affect circadian phase shifts. Normal indoor light intensity is 150 lux. High-intensity light can suppress melatonin production to an extent. Exposure to 3000-lux light was found to be near equivalent to 12,000 lux (daylight range, $10,000-25,000$ lux) in facilitating circadian 
adaptation. ${ }^{26}$ Blue light $(460-480 \mathrm{~nm})^{30}$ has the greatest effect on melanopsin receptors to delay melatonin production. This light is especially prominent in electronic screens that have high blue light content. Gooley et $\mathrm{al}^{29}$ showed that green light exposure can also delay melatonin production through cone photoreceptors (eg, red, blue, green). However, green light melatonin suppression decayed faster than blue, lasting half as long. If they intend to sleep directly after their shift, workers can decrease exposure to bright or high-wavelength light near the end of their shift. ${ }^{26}$ For example, orangetinted goggles have been shown to block the melatoninsuppressing effect of light significantly more than neutral gray density goggles. ${ }^{30}$ Other tools include red visor caps, ${ }^{31}$ lighting changes in the work environment, or the Redshift application for digital screens.

To our knowledge, no studies have been conducted to determine the optimal length of time needed with minimal blue light exposure to promote adequate melatonin production. Most sleep education entities recommend minimizing blue light exposure at least 2 hours before going to sleep. A 2009 randomized control trial $^{32}$ showed that blocking blue light for 3 hours before sleeping improved sleep quality.

In a 2008 study, ${ }^{23}$ participants who were exposed to bright light pulses during shift work wore dark sunglasses while leaving work in the daylight and then were exposed to outdoor light in the afternoon after waking, showed equal performance and duration of sleep as they had during day shifts. We recommend using orange-tinted goggles during the commute home and wide-spectrum blue lights during work hours to promote wakefulness. We also recommend increasing blue light exposure during the beginning of the shift and decreasing blue light exposure 2 to 3 hours before the end of the shift. Last, we recommend intermittent alternating of green and blue light exposure during work shifts to entrain the circadian cycle.

\section{Chronotypes}

Two major human chronotypes, morning chronotype and evening chronotype, are distinguished by the time
Table 4.

Tools to Improve Daytime Sleep in Shift Workers

\begin{tabular}{ll}
$\begin{array}{l}\text { External } \\
\text { Regulators }\end{array}$ & Tools \\
\hline Darkness & Eye pillows; blackout curtains \\
\hline Noise & $\begin{array}{l}\text { Television turned off; cellular phones } \\
\text { silenced; earplugs; white noise machine }\end{array}$ \\
\hline Temperature & Cold environment \\
\hline
\end{tabular}

of day that melatonin level begins to increase. For persons with the evening chronotype, melatonin increase begins several hours later than the morning chronotype (approximately 12 AM vs 9 PM, respectively). People with an evening chronotype have been found to adjust to shift work better than people with a morning chronotype. ${ }^{33}$ However, chronotype does not change the effectiveness of light therapy interventions. $^{34,35}$ Helping patients to identify chronotype allows physicians to discuss sleep hygiene practices with their patients.

Shift workers should focus on creating a sleep environment that promotes sleep and reduces sensory stimuli. It may be helpful if they eat and exercise at similar times of day. The exogenous entrainment of these external factors has the potential to improve synchrony of peripheral and central clock genes. ${ }^{36}$ Table 4 presents further examples of sleep hygiene practices that can improve circadian synchronicity.

\section{Sleep Disorder Comorbidities}

While shift workers are at risk for shift work sleep disorder, they are also at a heightened risk for other sleep disorders, such as sleep apnea. Shift workers with sleep deprivation and sleep apnea were found to be twice as likely to experience adverse cardiovascular events than shift workers without sleep disturbances. ${ }^{37}$ Shift workers should be screened for sleep duration, sleep apnea, and other sleep disorders to reduce the risk of adverse outcomes. Barger et $\mathrm{al}^{37}$ recommend the 10-item Berlin Questionnaire to screen for sleep apnea. ${ }^{37}$ Other sleep disorders, such as restless legs 
syndrome, periodic limb movement disorder, and rapid eye movement sleep disorder could also compound the risk of stroke and other adverse outcomes of metabolic syndrome. $^{38}$

\section{Nutrition}

Shift work may also be associated with lifestyle behaviors known to increase the risk of developing metabolic syndrome. A 2016 meta-analysis found that night shift workers do not consume more calories. ${ }^{39}$ Bonham et $\mathrm{al}^{36}$ theorized that misalignment of the circadian rhythm, food choice, and the timing of meals may partly explain why metabolic syndrome is more likely to develop in shift workers despite average caloric intake.

One review ${ }^{40}$ summarized the reciprocal relationship between nutritional intake and circadian rhythm disturbance. While light is the main external influencer of clock genes, which govern the central circadian rhythm, eating patterns can have a significant influence on the genes that govern the peripheral circadian rhythm of various organs. For this reason, timing meals with activity cycles and maintaining regular eating patterns have been found to reduce the development of obesity and metabolic syndrome. ${ }^{40}$ Specifically, people who eat more of their calories earlier in the day have been found to lose significantly more weight than those who eat the majority later in the day. ${ }^{41,42}$ Peripheral circadian rhythms dictate higher insulin sensitivity and diet-induced thermogenesis earlier in the morning for diurnal humans. ${ }^{40}$ In addition, high-fat diets have been found to dampen peripheral circadian rhythms, leading to worse metabolic outcomes. ${ }^{43}$ These combined findings underline the importance of regular timing of meals and timing meals in accordance with circadian rhythm and activity cycles for shift workers.

Night shift workers are significantly more likely not to follow a daily eating pattern than those who work day shifts. ${ }^{44}$ Several studies have also shown that shift workers are more likely to eat snacks higher in sugar and saturated fat while consuming less protein and vegetables. ${ }^{45,46}$ One study ${ }^{42}$ found that shift workers were more likely to skip meals. Those who skipped meals ( $\leq 2$ meals per day) had a higher body mass index. $^{42}$

Based on these findings, health professionals should screen shift workers for their eating patterns and the nutritional quality of their food. Shift workers should be encouraged to eat at similar times each day and to eat 3 meals or more per day to decrease the risk for metabolic syndrome. ${ }^{36,47}$ In addition, shift workers should be encouraged to eat more calories in the beginning of their wake cycle. Shift workers should be counseled on dealing with nighttime cravings of high-fat snacks by choosing protein-rich options. ${ }^{47}$ They should also be counseled to limit alcohol intake. ${ }^{40}$ To assist with establishing regular eating patterns, employers can cater meals and offer midnight snacks. ${ }^{48}$ Employers may also consider ensuring that employees have access to regularly timed breaks early in the shifts.

\section{Cortisol and Exercise}

Cortisol plays a key role in inflammation, which is a major factor in metabolic syndrome. However, its effects are dualistic, determined by timing and concentration. Basal cortisol levels and cortisol spikes without inflammatory stimuli do not contribute to inflammatory response. But spikes close to a stimulus will produce anti-inflammatory effects, such as decreasing leukocyte migration and monocytopenia. 49

Cortisol becomes proinflammatory via increasing cytokine release and cyclooxygenase enzymes when there is a delay between the stimulus and elevation of cortisol levels. Increased cyclooxygenase enzyme levels can lead to platelet hypersensitivity and increased risk for atherosclerotic diseases. ${ }^{50}$ Shift workers in particular have been shown to have increased cortisol levels and increased serum cyclooxygenase enzyme levels, which have both been linked to the development of metabolic syndrome and disruption of the circadian rhythm. ${ }^{50}$ Yeager et $\mathrm{al}^{49}$ found that mild spikes in cortisol were anti-inflammatory, whereas intermediate elevation in cortisol levels was proinflammatory. ${ }^{49}$ High levels of cortisol were found to be neither. ${ }^{52}$ They also 
showed that a 12-hour delay between the onset of the stimulus and elevated cortisol levels produced a proinflammatory state lasting for 6 days. ${ }^{49}$

Metabolic syndrome can promote proinflammation by both creating moderate elevation in cortisol and increasing inflammatory stimuli that are more likely to be delayed from the time of peak concentration spike. Metabolic syndrome has been associated with functional hypercortisolism. ${ }^{51}$ Because cortisol is linked to the circadian rhythm by the hypothalamic-pituitary-adrenal axis, modulation of cortisol may be a mechanism through which physical activity could synchronize the circadian rhythm and improve sleep quality. Physical activity has been shown to improve reentrainment of the circadian rhythm, the ability to fall asleep, and quality of sleep. ${ }^{20,52}$ Exercise has also been shown to reduce morning cortisol levels in individuals with metabolic syndrome. ${ }^{52}$

Physical activity can reestablish the circadian rhythm and decrease inflammation in shift workers, so it is important for physicians to understand night shift workers' current exercise habits and desire to exercise. Physicians can help develop a physical activity plan that is functional for shift workers' schedules. For example, shift workers should be advised to exercise at a similar time each day, at least 5 hours before they go to bed. ${ }^{36}$ In addition, they should be counseled to incorporate aerobic exercise into their physical activity, as it has specifically been indicated to improve sleep quality.

\section{Melatonin}

Prolonged exposure to light in the work environments of shift workers leads to changes in peaks and troughs of melatonin levels. When people experience these abnormal fluctuations in melatonin levels, they report poorer quality of sleep and increased need to nap. ${ }^{53}$ The use of melatonin supplements promotes phase shift advance and has been shown in a meta-analysis to improve sleep onset, efficiency, and duration. ${ }^{54}$ Exogenous melatonin administration works better when endogenous levels are low, as is often the case for elderly persons and persons who experience jet lag, insomnia, and circadian desynchrony disorders. ${ }^{55,56}$

For exogenous administration, melatonin can be bought over the counter as pills, liquid drops, or sublingual tablets. It is believed that excess doses of melatonin can worsen sleep cycles, with best effects reported to be at 0.3 to $0.5 \mathrm{mg} .{ }^{57}$ Oral pills are the most commonly used; however, sublingual tablets have more consistent and overall increased bioavailability ${ }^{58}$ because they are not subject to the first-pass effect. ${ }^{59}$

Melatonin has been shown to inhibit the harmful effects of fructose on clock genes and protect against reactive oxygen species. ${ }^{60}$ Melatonin has also been shown to regulate leptin and adiponectin secretion cycles, further underlying the reciprocal relationship of these hormonal cascades. ${ }^{61}$ Addressing these hormonal changes in hunger signaling and food cravings may offer therapeutic benefit for the prevention of metabolic syndrome in shift workers. Therefore, melatonin may also have benefits in weight management, which is also a concern for shift workers. Further research is needed to elucidate the relationship between weight management, insulin sensitivity, and exogenous melatonin.

\section{Pharmacologic Interventions}

Medications may be useful in promoting circadian balance (Table 5). Anything that can affect hormone equilibrium can be beneficial to patients with metabolic syndrome. Using medications to regulate sleep and wake cycles can reciprocally benefit metabolic disorders.

\section{Osteopathic Manipulative Treatment}

Shift work has been linked to poor regulation of the autonomic nervous system, as measured by heart rate variability. ${ }^{62}$ This poor regulation could play a role in shift workers' increased risk for metabolic syndrome. One study of emergency medical technicians found that those working a 24-hour shift were more likely to have low heart rate variability and a higher risk of cardiovascular disease. ${ }^{63}$ Osteopathic manipulative treatment 
Table 5.

Possible Pharmacologic Interventions to Improve Circadian Balance in Shift Workers

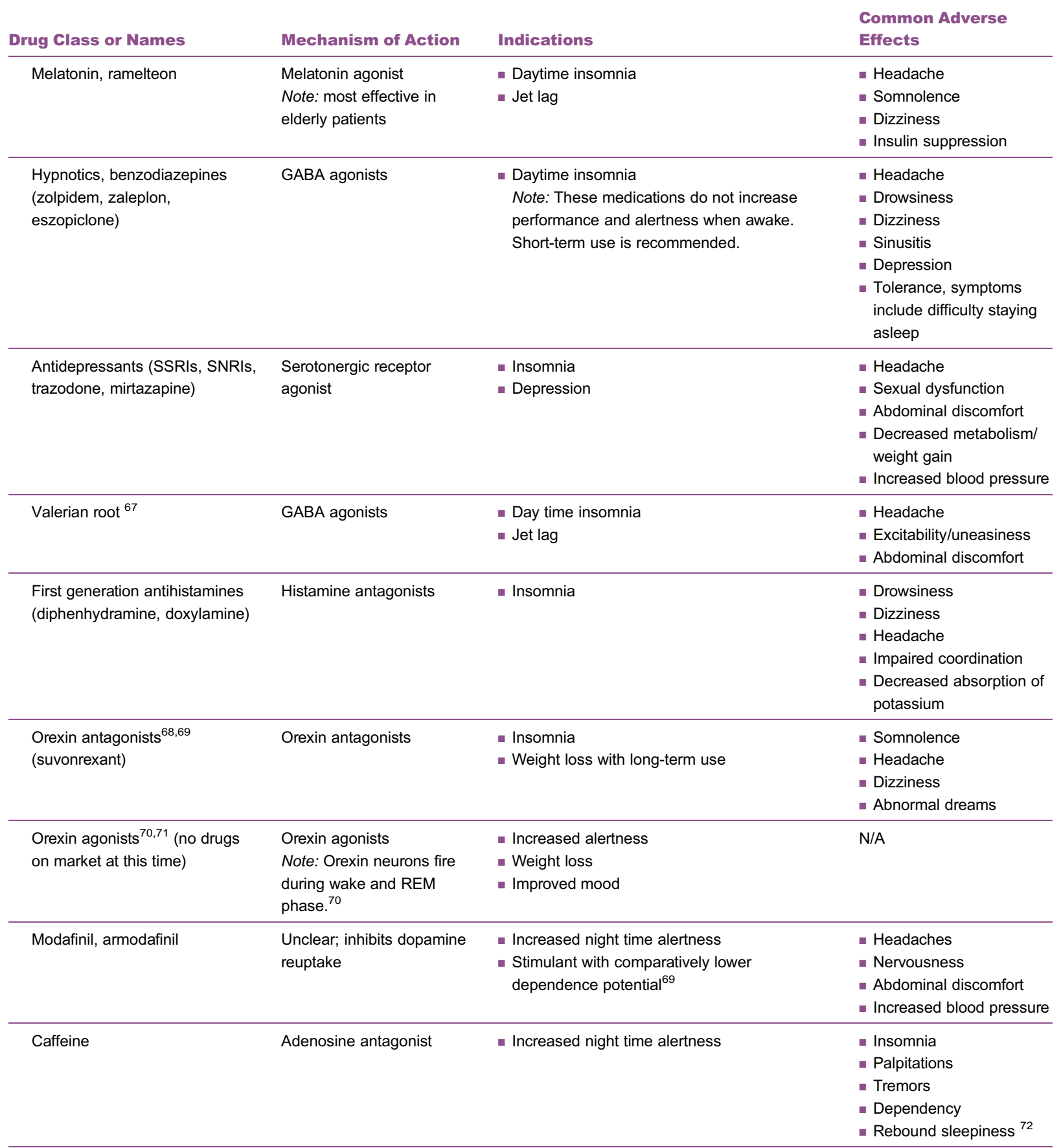

Abbreviations: GABA, $\gamma$-aminobutyric acid; NA, not applicable; NREM, non-rapid eye movement; REM, rapid eye movement; SNRI, serotonin-norepinephrine reuptake inhibitor; SSRI, selective serotonin reuptake inhibitor. 
(OMT) has been shown to improve both heart rate variability and sleep latency. ${ }^{64,65}$ For these reasons, OMT should be considered as part of the treatment plan for shift workers at risk for metabolic syndrome. These techniques can be used to both reset autonomic tone and to immediately improve sleep quality.

\section{Conclusion}

Shift workers should be screened for signs of circadian discordance. Early identification of circadian discordance in this population is essential to reduce the risk of developing metabolic syndrome. Primary prevention through lifestyle modifications (eg, sleep hygiene practices, light therapy, eating and exercise habits, pharmaceuticals, and OMT) is the best way to address both the quality of life and the long-term health care burdens in shift workers.

In addition, workplace adjustments may have an even greater effect on improving sleep quality, hormonal balance, and overall health. Systemic changes in shift-work scheduling, light exposure, and better nutrition offerings may be the best ways to improve circadian rhythm disorders and reduce mortality associated with metabolic syndrome. As physicians, we should discuss these concerns with patients, local employers, and within the community.

With few clinical trials conducted to evaluate clinical and workplace interventions directed at shift workers with a nocturnal or rotational sleep-wake pattern, future research on the influence of lifestyle factors and pharmaceutical interventions should be done to determine the most effective strategy to reduce the burden of metabolic syndrome in this population.

\section{References}

1. Boivin $D$, Boudreau P. Impacts of shift work on sleep and circadian rhythms. Pathologie Biologie. 2014;62(5):292-301. doi:10.1016/j. patbio.2014.08.001

2. McMenamin TM. A time to work: recent trends in shift work and flexible schedules. Monthly Labor Review. Dec 2007:3-15.

3. Proper $\mathrm{KI}$, van de Langenberg D, Rodenburg W, et al. The relationship between shift work and metabolic risk factors: a systematic review of longitudinal studies. Am J Prev Med. 2016;50(5):e147-e157. doi:10.1016/j.amepre.2015.11.013

4. Saenz R. A Demographic Profile of US Workers Around the Clock. Washington, DC: Population Reference Bureau; 2008.

5. Guo Y, Liu Y, Huang X, et al. The effects of shift work on sleeping quality, hypertension and diabetes in retired workers. PLoS One. 2013;8(8):e71107. doi:10.1371/journal.pone.0071107

6. Pan A, Schernhammer ES, Sun Q, Hu FB. Rotating night shift work and risk of type 2 diabetes: two prospective cohort studies in women. PLoS Med. 2011;8(12):el001141. doi:10.1371/journal.pmed.1001141

7. Ferri P, Guadi M, Marcheselli L, Balduzzi S, Magnani D, Di Lorenzo R. The impact of shift work on the psychological and physical health of nurses in a general hospital: a comparison between rotating night shifts and day shifts. Risk Manag Healthc Policy. 2016;9:203-211. doi:10.2147/RMHP.S115326

8. Nena E, Katsaouni M, Steiropoulos $P$, Theodorou E, Constantinidis TC, Tripsianis G. Effect of shift work on sleep, health, and quality of life of health-care workers. Indian J Occup Environ Med. 2018;22 (1):29-34. doi:10.4103/ijoem.IJOEM_4_18

9. Loef B, van der Beek AJ, Holtermann A, Hulsegge G, van Baarle D, Proper KI. Objectively measured physical activity of hospital shift workers. Scand J Work Environ Health. 2018;44(3):265-273. doi:10.5271/sjweh.3709

10. Loef B, Hulsegge G, Wendel-Vos GC, et al. Non-occupational physical activity levels of shift workers compared with non-shift workers. Occup Environ Med. 2016;74(5):328-335. doi:10.1136/oemed-2016-103878

11. Fonken LK, Nelson RJ. The effects of light at night on circadian clocks and metabolism. Endocr Rev. 2014;35(4):648-670. doi:10.1210/ er.2013-1051

12. Åkerstedt T, Wright KP Jr. Sleep loss and fatigue in shift work and shift work disorder. Sleep Med Clin. 2009;4(2):257-271. doi:10.1016/j. jsmc.2009.03.001.

13. Stender SRS, Burghen GA, Mallare JT. The role of health care providers in the prevention of overweight and type 2 diabetes in children and adolescents. Diabetes Spectrum. 2005;18(4):240-248. doi:10.2337/diaspect.18.4.240

14. Challet E. Keeping circadian time with hormones. Diabetes Obes Metab. 2015;17:76-83. doi:10.1111/dom.12516

15. Touati H, Ouali-Hassenaoui $S$, Dekar-Madoui A, Challet E, Pévet $P$, Vuillez P. Diet-induced insulin resistance state disturbs brain clock processes and alters tuning of clock outputs in the sand rat, Psammomys obesus. Brain Res. 2018;1679:116-124. doi:10.1016/j. brainres.2017.11.018

16. Kajimoto J, Matsumura R, Node K, Akashi M. Potential role of the pancreatic hormone insulin in resetting human peripheral clocks. Genes Cells. 2018;23(5):393-399. doi:10.1111/gtc.12582

17. Scheer FA, Hilton MF, Mantzoros CS, Shea SA. Adverse metabolic and cardiovascular consequences of circadian misalignment. Proc Natl Acad Sci U S A. 2009;106(11):4453-4458. doi:10.1073/ pnas. 0808180106

18. Morris CJ, Purvis TE, Mistretta J, Scheer FA. Effects of the internal circadian system and circadian misalignment on glucose tolerance in chronic shift workers. J Clin Endocrinol Metab. 2016;101 (3):1066-1074. doi:10.1210/jc.2015-3924

19. Qian J, Dalla Man C, Morris CJ, Cobelli C, Scheer FAJL. Differential effects of the circadian system and circadian misalignment on insulin 
sensitivity and insulin secretion in humans. Diabetes Obes Metab. 2018;20(10):2481-2485. doi:10.1111/dom.13391

20. Thorpy MJ. Managing the patient with shift-work disorder. J Fam Pract. 2010;59(1 suppl):S24-S31.

21. Watson NF, Badr MS, Belenky G, et al. Recommended amount of sleep for a healthy adult: a joint consensus statement of the American Academy of Sleep Medicine and Sleep Research Society. Sleep. 2015;11(6):591-592. doi:10.5664/jcsm.4758

22. Weitzman ED, Czeisler CA, Coleman RM, et al. Delayed sleep phase syndrome. a Chronobiological disorder with sleep-onset insomnia. Arch Gen Psychiatry. 1981;38(7):737-746.

23. Smith MR, Eastman Cl. Night shift performance is improved by a compromise circadian phase position: study 3. circadian phase after 7 night shifts with an intervening weekend off. Sleep. 2008;31 (12):1639-1645.

24. Santhi, Nayantara, et al. The impact of sleep timing and bright light exposure on attentional impairment during night work. J Biol Rhythms. 2008;23(4):341-352. doi:10.1177/0748730408319863

25. Postnova S, Fulcher R, Braun HA, Robinson PA. A minimal physiologically based model of the HPA axis under influence of the sleep-wake cycles. Pharmacopsychiatry. 2013;46(suppl 1):S36-S43. doi:10.1055/s-0033-1333763

26. Barion A, Zee P C. A clinical approach to circadian rhythm sleep disorders. Sleep Med. 2007:8(6):566-577

27. Cruz C, Detwiler C, Nesthus T, Boquet A. Clockwise and counterclockwise rotating shifts: effects on sleep duration, timing, and quality. Aviat Space Environ Med. 2003;74(6 pt 1):597-605.

28. Souman JL, Borra T, de Goijer I, Schlangen LJM, Vlaskamp BNS, Lucassen MP. Spectral tuning of white light allows for strong reduction in melatonin suppression without changing illumination level or color temperature. J Biol Rhythms. 2018;33(4):420-431. doi:10.1177/ 0748730418784041

29. Gooley JJ, Rajaratnam SM, Brainard GC, Kronauer RE, Czeisler CA Lockley SW. Spectral responses of the human circadian system depend on the irradiance and duration of exposure to light. Sci Trans Med. 2010;2(31):31ra33. doi:10.1126/scitransImed.3000741

30. Boivin DB, Boudreau P, Tremblay GM. Phototherapy and orange-tinted goggles for night-shift adaptation of police officers on patrol. Chronobiol Int. 2012;29(5):629-640. doi:10.3109/07420528.2012.675252

31. Higuchi S, Fukuda T, Kozaki T, Takahashi M, Miura N. Effectiveness of a red-visor cap for preventing light-induced melatonin suppression during simulated night work. J Physiol Anthropol. 2011;30(6):251-258. doi:10.2114/jpa2.30.251

32. Burkhart K, Phelps JR. Amber lenses to block blue light and improve sleep: a randomized trial. Chronobiol Int. 2009;26(8):1602-1612. doi:10.3109/07420520903523719

33. Figueiro MG, Plitnick B, Rea MS. The effects of chronotype, sleep schedule and light/dark pattern exposures on circadian phase. Sleep Med. 2014;15(12):1554-1564. doi:10.1016/j.sleep.2014.07.009

34. Knapen SE, Gordijn MC, Meesters Y. The relation between chronotype and treatment outcome with light therapy on a fixed time schedule. J Affect Disord. 2016;202:87-90. doi:10.1016/j.jad.2016.05.009

35. Brum MC, Filho FF, Schnorr CC, Bottega GB, Rodrigues TC. Shift work and its association with metabolic disorders. Diabetol Metab Syndr. 2015;7:45. doi:10.1186/s13098-015-0041-4
36. Bonham MP, Bonnell EK, Huggins CE. Energy intake of shift workers compared to fixed day workers: a systematic review and meta-analysis. Chronobiol Int. 2016;33(8):1086-1100. doi:10.1080/ 07420528.2016.1192188

37. Barger LK, Rajaratnam SMW, Cannon CP, et al. Short sleep duration, obstructive sleep apnea, shiftwork, and the risk of adverse cardiovascular events in patients after an acute coronary syndrome. J Am Heart Assoc. 2017;6(10):e006959. doi:10.1161/JAHA.117.006959

38. McDermott M, Brown DL, Chervin RD. Sleep disorders and the risk of stroke. Expert Rev Neurother. 2018;18(7):523-531. doi:10.1080/ 14737175.2018.1489239

39. Amani R, Gill T. Shiftworking, nutrition and obesity: implications for workforce health-a systematic review. Asia Pac J Clin Med. 2013;22 (4):505-515. doi:10.6133/apjcn.2013.22.4.11

40. Potter GD, Cade JE, Grant PJ, Hardie LJ. Nutrition and the circadian system. Br J Nutr. 2016;116(3):434-442. doi:10.1017/ S0007114516002117

41. Bo S, Musso G, Beccuti G, et al. Consuming more of daily caloric intake at dinner predisposes to obesity. a 6-year population-based prospective cohort study. PLoS One. 2014;24;9(9):e108467. doi:10.1371/journal.pone. 010846

42. Garaulet M, Gomez-Abellan P, Alburquerque-Bejar JJ, Lee YC, Ordovás JM, Scheer FA. Timing of food intake predicts weight loss effectiveness. Int J Obes (Lond). 2013;37(4):604-611. doi:10.1038/ ijo.2012.229

43. Kohsaka A, Laposky AD, Ramsey KM, et al. High-fat diet disrupts behavioral and molecular circadian rhythms in mice. Cell Metab. 2007;6(5):414-421. doi:10.1016/j.cmet.2007.09.006

44. Sudo N, Ohtsuka R. Nutrient intake among female shift workers in computer factory in Japan. Int J Food Sci Nutr. 2001;52(4):367-378 doi:10.1080/09637480120057530

45. Morikawa Y, Miura, K, Sasaki S, et al. Evaluation of the effects of shift work on nutrient intake: a cross-sectional study. J Occup Health. 2008;50(3):270-278. doi:10.1539/joh.17116

46. Fukumura T, Yoshita K, Tabata M. Associations among physical condition, life hour, and dietary intake male Japanese shift workers: physical condition and lifestyle survey of male Japanese shift workers [in Japanese]. Sangyo Eiseigaku Zasshi. 2015;57(6):286-296. doi:10.1539/sangyoeisei.B15015

47. Yoshizaki T, Kawano Y, Noguchi O, et al. Association of eating behaviours with diurnal preference and rotating shift work in Japanese female nurses: a cross-sectional study. BMJ Open. 2016;6(11): e011987. doi:10.1136/bmjopen-2016-011987

48. Hemiö K, Puttonen S, Viitasalo K, Härmä M, Peltonen M, Lindström J. Food and nutrient intake among workers. Occup Environ Med. 2015l;72(7):513-520. doi:10.1136/ oemed-2014-102624

49. Yeager MP, Pioli PA, Guyre PM. Cortisol exerts bi-phasic regulation of inflammation in humans. Dose Response. 2011;9(3):332-347. doi:10.2203/dose-response.10-013.Yeager

50. Isidori AM, Venneri MA, Graziadio C, et al. Effect of once-daily, modified-release hydrocortisone versus standard glucocorticoid therapy on metabolism and innate immunity in patients with adrenal insufficiency (DREAM): a single-blind, randomised controlled trial. Lancet Diabetes Endocrinol. 2018;6(3):173-185. doi:10.1016/ s2213-8587(17)30398-4 
51. Anagnostis P, Athyros VG, Tziomalos K, Karagiannis A, Mikhailidis DP. The pathogenetic role of cortisol in the metabolic syndrome: a hypothesis. J Clin Endocrinol Metab. 2009;94(8):2692-2701. doi:10.1210/jc.2009-037

52. Nakao T, Yasumoto A, Tokuoka S, et al. The impact of night-shift work on platelet function in healthy medical staff. J Occup Health. 2018;60 (4):324-332. doi:10.1539/joh.2018-0027-fs

53. Brzezinski A, Vangel M, Wurtman R, et al. Effects of exogenous melatonin on sleep: a meta-analysis. Sleep Med Rev. 2005;9(1):41-50. doi:10.1016/j.smrv.2004.06.004

54. Zhdanova IV, Wurtman RJ, Balcioglu A, Kartashov AI, Lynch HJ. Endogenous melatonin levels and the fate of exogenous melatonin: age effects. J Gerontol A Biol Sci Med Sci. 1998;53(4):B293-B298. doi:10.1093/gerona/53a.4.b293

55. Sack RL, Hughes RJ, Edgar DM, Lewy AJ. Sleep-promoting effects of melatonin: at what dose, in whom, under what conditions, and by what mechanisms? Sleep. 1997;20(10):908-915. doi:10.1093/sleep/ 20.10 .908

56. Vural EM, van Munster BC, de Rooij SE. Optimal dosages for melatonin supplementation therapy in older adults: a systematic review of current literature. Drugs Aging. 2014;31(6):441-451. doi:10.1007/ s40266-014-0178-0

57. Wurtman RJ. Low doses of melatonin promote sleep onset and maintenance in older people-an update. US Neurology. 2014;10 (2):117-119.

58. van Geijlswijk I. The relative bio-availability of oral and oromucosal melatonin in different formulations in healthy human volunteers. ClinicalTrials.gov website. https://clinicaltrials.gov/ct2/show/study/ NCT02107079. Updated April 8, 2014. Accessed December 12, 2019.

59. Valenzuela-Melgarejo F, Caro-Díaz C, Cabello-Guzmán G. Potential crosstalk between fructose and melatonin: a new role of melatonininhibiting the metabolic effects of fructose. Int J Endocrinol. 2018;2018:7515767. doi:10.1155/2018/7515767

60. Galano A, Tan DX, Reiter RJ. Melatonin: a versatile protector against oxidative DNA damage. Molecules. 2018;23(3):530. doi:10.3390/ molecules 23030530

61. Pagel JF, Parnes BL. Medications for the treatment of sleep disorders: an overview. Prim Care Companion J Clin Psychiatry. 2001;3(3):118-125. doi:10.4088/pcc.v03n0303
62. Togo F, Takahashi M. Heart rate variability in occupational health -a systematic review. Ind Health. 2009;47(6):589-602. doi:10.2486/ indhealth. 47.589

63. Neufeld EV, Carney JJ, Dolezal BA, Boland DM, Cooper CB. Exploratory study of heart rate variability and sleep among emergency medical services shift workers. Prehosp Emerg Care. 2017;21 (1):18-23. doi:10.1080/10903127.2016.1194928

64. GilesPD, Hensel KL, Pacchia CF, Smith ML. Suboccipital decompression enhances heart rate variability indices of cardiac control in healthy subjects. J Altern Complement Med. 2013;19 (2):92-96. doi:10.1089/acm.2011.0031

65. Cutler, Holland BS, Stupski BA, Gamber RG, Smith ML. Cranial manipulation can alter sleep latency and sympathetic nerve activity in humans: a pilot study. J Altern Complement Med. 2005;11(1):103-108. doi:10.1089/acm.2005.11.103

66. Stanchina ML, Abu-Hijleh M, Chaudhry BK, Carlisle CC, Millman RP. The influence of white noise on sleep in subjects exposed to ICU noise. Sleep Med. 2005;6(5):423-428. doi:10.1016/j.sleep.2004.12.004

67. Thomas K, Canedo J, Perry PJ. Effects of valerian on subjective sedation, field sobriety testing and driving simulator performance. Accid Anal Prev. 2016;92:240-244. doi:10.1016/j.aap.2016.01.019

68. Marston O, Williams R, Canal M, Samuels R, Upton N, Piggins H. Circadian and dark-pulse activation of orexin/hypocretin neurons. Mol Brain. 2008;1(1):19. doi:10.1186/1756-6606-1-19

69. Butterick TA, Billington CJ, Kotz CM, Nixon JP. Orexin: pathways to obesity resistance? Rev Endocr Metab Disord. 2013;14(4):357-364. doi:10.1007/s11154-013-9259-3

70. Mieda M, Sakurai T. Orexin (hypocretin) receptor agonists and antagonists for treatment of sleep disorders. Rationale for development and current status. CNS Drugs. 2013;27(2):83-90. doi:10.1007/s40263-012-0036-8

71. Irukayama-Tomobe $\mathrm{Y}$, Ogawa $\mathrm{Y}$, Tominaga $\mathrm{H}$, et al. Nonpeptide orexin type-2 receptor agonist ameliorates narcolepsy-cataplexy symptoms in mouse models. Proc Natl Acad Sci U S A. 2017;114(22):5731-5736. doi:10.1073/pnas.1700499114

72. Roehrs T, Roth T. Caffeine: sleep and daytime sleepiness. Sleep Med Rev. 2008;12(2):153-162. doi:10.1016/j.smrv.2007.07.004

(๑) 2020 American Osteopathic Association 